\title{
INNOVATIVE CONCEPTUAL DESIGN FOR PATENTABILITY. CASE STUDY OF THE DOUBLE COMPARTMENT THERMOS CONTAINER
}

\author{
Bogdan BUCUR ${ }^{1}$, Teodora BIRIȘ ${ }^{2}$ \\ 1,2 "George Emil Palade" University of Medicine, Pharmacy, Science and \\ Technology of Târgu Mureş, Gh. Marinescu 38, România \\ 1bogdan.bucur@umfst.ro \\ 2teodorabiris1@gmail.com
}

\begin{abstract}
Any initial product started from a more or less flexible idea, or a patented idea transposed into a manufactured product. This idea takes a new development following the study of the marketing market, analysis studies and all we need for technological opportunity, outlining at the same time stage by stage the prototype concept. The prototype variant is again subjected to a systemic analysis that defines and optimizes the final product, as well as the technological flow associated with the entire manufacturing process applied on the concept. The paper proposes a synthesis analysis on innovative conceptual design. The case study presented in this paper shows a reserch study applied on the industrial product for which the patent was obtained, respectively a double compartmented thermos container [17].
\end{abstract}

Keywords: conceptual engineering design, patent, 3D modeling, case study, innovative concept

\section{Introduction}

The concepts of engineering design and conceptual innovation it can be described as a set of decisions made to solve a certain set of requirements associated with the industrial product. Within the product development process, there are several stages: idea generation, product definition also called product planning, [4] conceptual design, detail design and functional design [5], [8]. In Fig. 1, you can see the analysis of the structure of the design process associated with the product development.

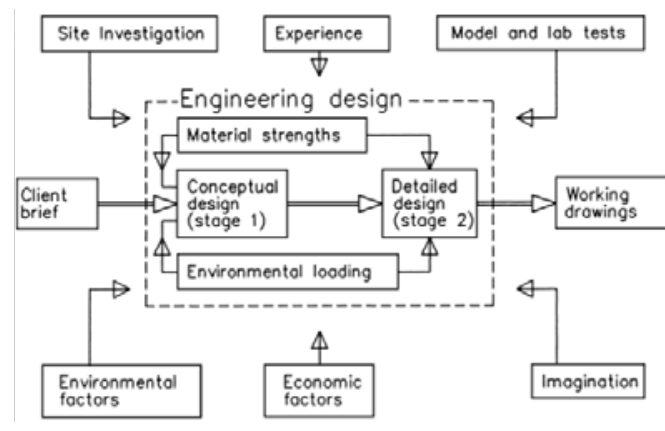

Fig. 1: Product planning [8]

The design process is a ubiquitous activity and appreciated probebly by the almost of the consumers, proactive and competitives. All the designers benefit from modern conceptual tools such as process models, methods and advanced design principles to develop an innovative concept from the start-up phase, starting

(C) 2021 Published by University Press. This is an open access article under the CC BY-NC-ND license (http://creativecommons.org/licenses/CC-BY-4.0/) 
from the idea and materializing the whole stage of the concept development process. All these stages are included in the life cycle diagram of any product, respectively it includes the following stages: documentation-research, prototyping, launch, development, maturity and decline, [2],[3].

The conceptual design phase is the most important step in competing engineering after the project planning or product definition phase. About eighty percent of a product's life cycle costs are incurred through systemic analysis, design solutions, such as material selections and manufacturing processes at this stage, [1] Conceptual design includes the definition, exploration, evaluation and selection of the concept.

The design criteria of the industrial product are: functionality (a component consists of different parts. The functional part is the one that really has a critical assignment that leads to the performance of the component. The non-functional part does not have a major work in the existence of the industrial product, but has something to deals with maintenance, coatings, inspection and aesthetic value and its must be minimized in order to have a low production cost, [6], [7]. The particularity of the product is defined by: manufacturing problems, complexity, choice and definition of materials, the precision class of manufacturing parts, tolerances and surface finishing, surface treatment, process cost, resulting waste, handling and assembly. All these stages of analysis it can be included by the design phase through simulations and situation analyzes approached, you can see in Fig.2, all the decision of analysis structure.

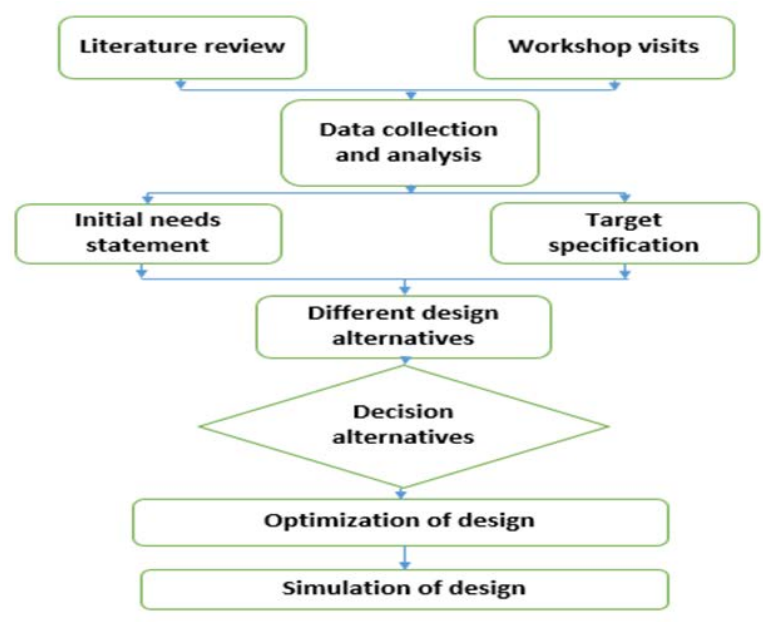

Fig. 2: Decisions of analysis structure [8]

The innovation concept development is defined and consists of three main development processes:

1. The process of creating knowledge from public or industrial research;

2. The process of developing the new product, which transforms knowledge into a new product and
3. The success of the product on the market place, which depends on the functionality of the product and the organizational skills and competencies of the company to produce them at a competitional price and quality and appropriately market-oriented, [13].

\section{Research method}

The innovative ideas are generated in principle by the user's comfort and ergonomics, starting from a study based on the marketing functions, [9], there are presented in Fig. 3.

Following the research study on alternatives and methods of project development we can considered: brainstorming, method of giving up and voting (D\&R) or intuitive skills of the designer to choose the most feasible and effective alternative of the best meet the needs customers, [9],[10]. The selection of the best alternative solution was made by using the engineering design weighted score matrix. The factors will be consider involve is: green design concepts, efficiency, ergonomic design considerations and safety, among others.

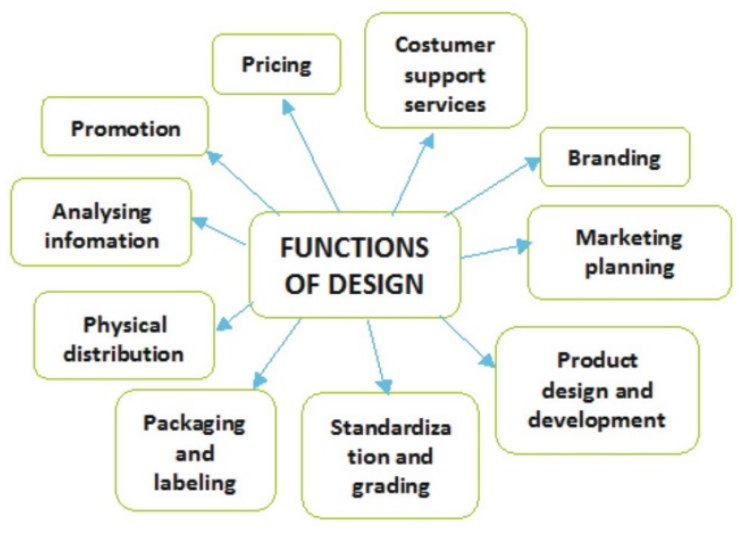

Fig. 3: Marketing functions [9]

All these functions of the marketing analysis must be taken into account for the development of the innovative structure of the product considered.

The paper presents a case study that identifies and defines an innovative design solution by analyzing the technical solutions identified from the others reference patents applied on the product, respectively on a thermos container, [14],[15],[16], developing a new innovative concept, consisting of a new reference patent [17].

\section{Case Study Description}

The idea of the case study defines the identification of a system of containers assembled in a single thermos-type body, which has a multifunctionality, namely: storage, transport and use of two fluids at different temperatures and which do not diffuse between them during their successive use the fluidesFor the beginning, it is necesary to make a research study is defined regarding the innovative 
ideas present in different patents of inventions associated with the solution of the idea, establishing at the same time the strategy of analysis and generation of ideas, [12]. The invention proposes for a doublecompartment thermos container a technical solution for isolating for two compartments and using in turn the liquids one by one at the different temperatures, without mixing them.

The thermos-type containers with several compartments are known, differentiating the technical solutions for sealing guiding the liquid to emptying, the following patents are being relevant.

The next patent, US 2011089180 A1 [14] its refers to a thermos with two separate chambers containing two different liquids that maintain their temperatures, without being mixed even when poured and which is configured as a modular set having containers with different volumes and the cover system is adaptable to the main body with different sizes. The next patent is US 5921440 A [15], it can describes a multicompartment container for different types of packaged liquids for distribution by the user either individually or together. The next patent is US 3076573 A [16], it refers to a compartmentalized dispenser suitable for dispensing two fluids from a bottle, comprising a portion of the hollow body and a fluid-tight vertical partition extending between the upper and lower part, forming two compartments with an annular opening at the top having substantially the same circumferential configuration.On the following the research study on patents identified as an innovative source of ideas, the proposed innovative technical solution has a modular system of lids to capture, guide and seal fluid containers, separate orientation of fluids to emptying or filling is done by using a innovative and reliable solution that allows the selection of fluids by indexingblocking. Thus, the technical problem solved by the container is the separate of the liquids use at the different temperatures in two separate compartments and the innovative caracteristic solution will be protected by the patent [17].

The mode of operation, as well as the component parts of the thermos are presented in detail in a concept sketch, you can see in Fig. 4 and Fig. 5. The thermos includes at the bottom an outer container (12) in which are fixed by means of a solid thermal insulator (13) two inner glass containers (14 and 15) with double walls each, at the top of the outer container is inserted a disc -spacer support (9), which ensures the locking of the glass containers (14) and (15), and the fixing is done by threaded assembly of the upper lid (6) in the lower outer container (12), the liquid capture chamber (4) it is centered and fixed in the lid (6) by means of a system of balls arranged in two different sections (7 and 8), which ensures the rotation and fixing of the liquid capture chamber (4) to the lid (6). The liquid capture chamber (4) has a rotating locking-indexing system at the bottom by means of a ball (2) and a pretensioning spring (1) with the role of locking-indexing in the hemispherical seat (16), thus allows indexing by rotating the liquid capture chamber (4) in four successive positions.

In section $\mathrm{A}-\mathrm{A}$, we can see the sealing plug discs (10) and the drain / fill nozzle (3) fixed in the body of the liquid capture chamber (4) are presented, in to the fluid containers (14 and 15) they are arranged equidistantly on a defined diameter. The thermos is closed at the top by means of the cup-lid (5) which is screwed into the neck of the top lid (6) and by means of the inner conical surface of the cup-lid (5) the neck of the liquid capture chamber is closed (4), at the same time by indexing the four locking-sealing positions of the liquid capture chamber (4) with respect to the spacer support disc (9) and the inner containers (14 and $15)$ the following positions are ensured:

- switch on the position " 0 " by means of the nozzle (3) the access of the fluid from the outside in to the container (15) is opened by means of the liquid collection chamber (4) and closes the access to the container (14) by closing with the plug-disc (10);

- by rotating and indexing the liquid collection chamber (4) to position " 1 " the access between the inner fluid containers (14 and 15) and the liquid collection chamber (4) with the outside of the thermos is blocked by means of the plug discs (10);

- by rotating and indexing the liquid collection chamber (4) move on to position " 2 " by means of the nozzle (3) the access of the fluid in the container (14) is opened from the outside through the liquid collection chamber (4) and the access of the fluid in the container is closed (15) by plugging with the plug (10); - by rotating and indexing the liquid collection chamber (4) switch on the position '3', it can close again the access of the fluids in the inner containers (14 and 15);

- for the cycle will resumed at a further rotation and subsequent indexing.

In section B-B you can see the highlighted the asymmetrical shape of the two inner containers (14 and $15)$ with double walls each, fixed in the outer container of the thermos (12), by means of a solid thermal insulator. The cup-lid (5) it has multiple functions, namely: seals the thermos and blocks access to the liquid collection chamber (4), while ensuring the function of the lid by screwing and assembly with the outer container (12), overall the geometric shape of the lid- glass harmoniously complements the aesthetics and ergonomics of the thermos.

Section A-A: presents the identification of the position of the three sealing disc-plug type (10), respectively of the nozzle (3);

Section B-B: you can see in cross section the geometric shape of the fluid containers $(14,15)$ assembled in the lower container (12). 


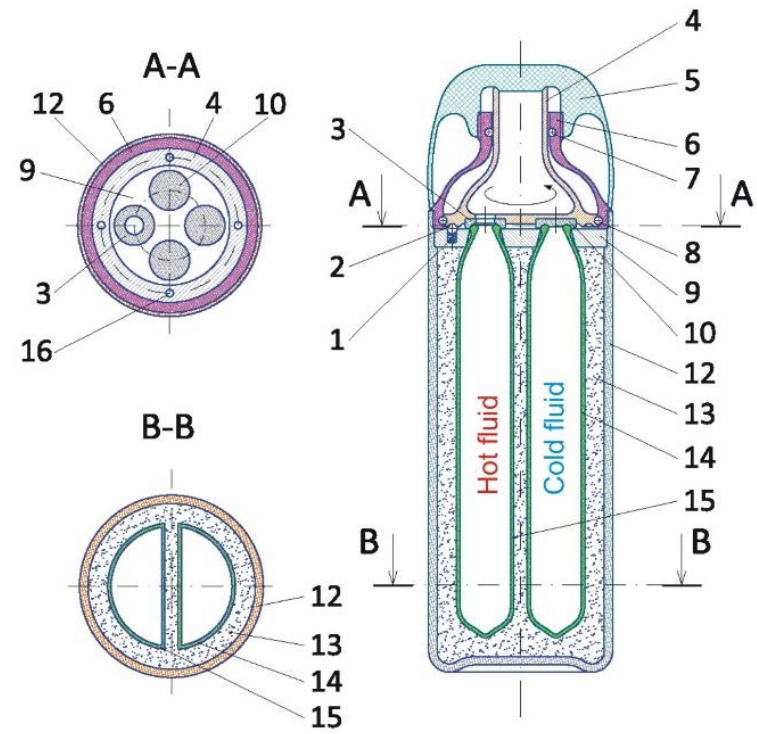

Fig. 4: The materialization of the sketch of the thermos assembly patent idea: 1 .compression spring, 2 .induction ball, 3.dozzle, 4.liquid capture chamber, 5.glass lid, 6.upper lid, 7.inner circle, 8.bowel row bottom, 9.spacer-support disc, 10. sealing plug-disc, 12. exterior bottom container, 13.solid thermal insulation, 14.double-walled cold fluid container, 15.double-walled hot fluid container, [17]

The basic part of the assembly it is representativ by the fluid capture chamber (4), you can see the assembly in Fig. 5.
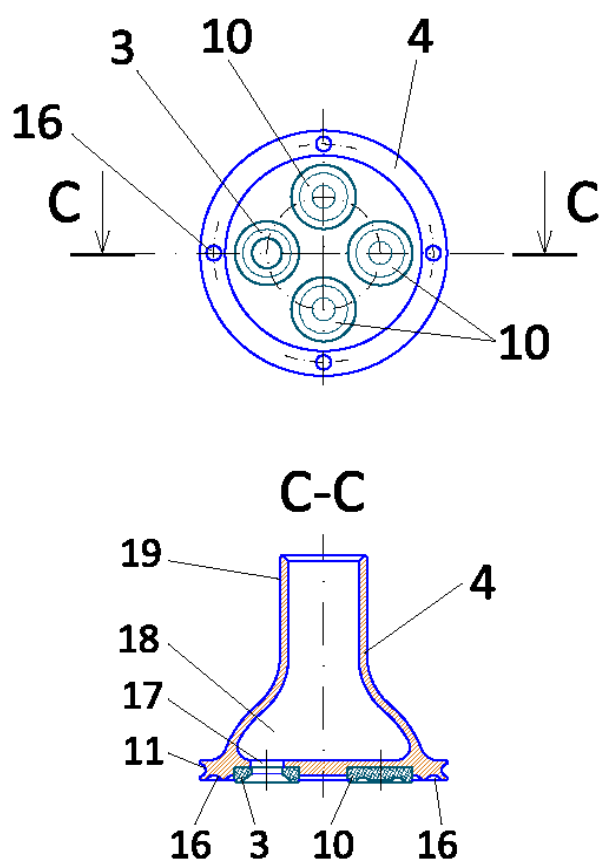

Fig. 5: The fluid capture chamber assembly (4): nozzle (3), liquid capture chamber (4), sealing plug-disc (10), semicircular channel (11), spherical half-cup (16), drain / filling hole (17), fluid capture cavity of variable section (18), ribbed collar (19), [17].

Section C-C you can see the assembly of parts 3, 4 and 10. The closing part of the thermos container is outlined in Fig. 6.

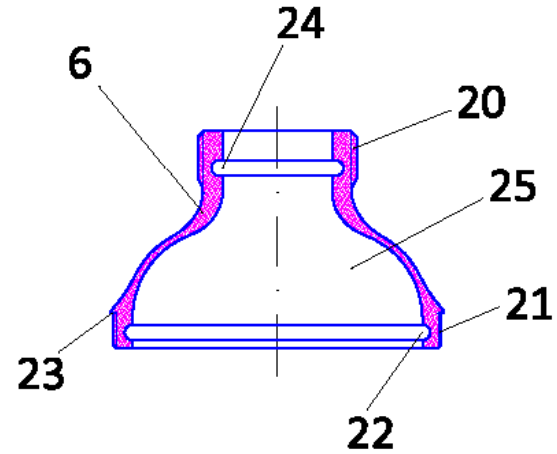

Fig. 6: The upper cover (6): threaded collar (20), outer thread (21), lower semicircular channel (22), threshold collar (23), upper semicircular channel (24), tubular cavity with variable section (25), [17]

With the patenting of the innovative solution [17], the final stage of the development analyze is defined by the parameterized design of the concept, analyzing the technical solutions implemented and reported for analysis for the first series of manufacturing the product. Among the aspects we can study: analyzed from a technological and economic point of view, the materials associated with each component and the technology associated on the benchmark, as well as the identification of materials and ergonomic proportions of the parts component applied to the product considered, [11].

In Fig.7, it can be seen the assembly design of the double compartmentalized thermos, the 3D model parameterized in the Autodesk Inventor environment.

\section{Conclusions}

The purpose of this case study is not to provide academic evidence of the validity of the methodology, but rather to gain practical experience and sources of ideas for learning and deepening innovative technical solutions applied on the products.

This paper presented an integrated model of the innovation process that combines patented reference concepts with the inovation idea solutions, while defining an original patented solution, [17]. The model follows a life cycle approach from the initial idea to the exploitation of new innovation solution on the market place.

The paper as a whole, offers a new field of application for the management and deepening of innovative conceptual design, as well as the exploitation of engineering management in order to optimize the synthesis of innovative concepts. 


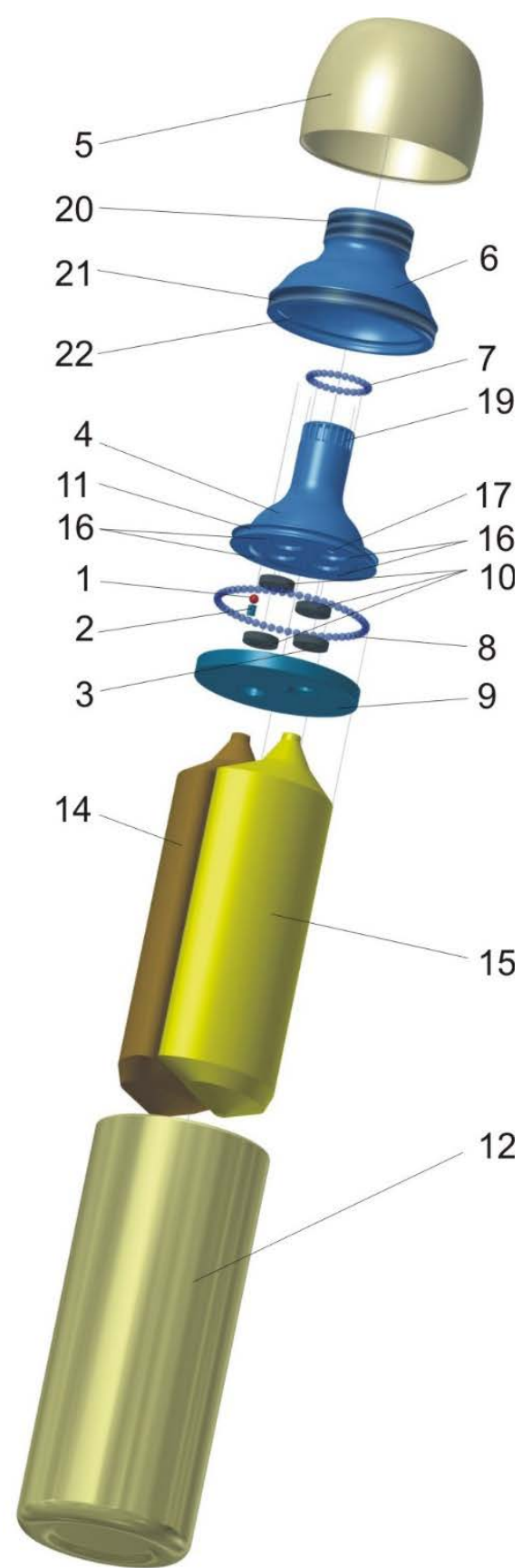

Fig. 7: The exploded assembly: Double compartment thermos container

\section{References}

[1] Albert, Robert S. and Mark A. Runco, "A History of Research on Creativity," in Handbook of Creativity, Robert J. Sternberg editor, Cambridge University Press, 1999;

[2] Assink, M., Inhibitors of disruptive innovation capability: a conceptual model, European Journal of Innovation Management, Vol. 9 no. 2, pp. 215233, 2006;

[3] Bilén, Sven G. and Richard F. Devon, "nnovative engineering Design Education,"International Conference on Engineering Design (ICED), Melbourne, August 15-18, 2005;

[4] Camarda, Charles J., A Return to Innovative Engineering Design, Critical Thinking, and Systems Engineering, Keynote address presented at The International Thermal Conductivity Conference (ITCC) and the International Thermal Expansion symposium (ITES), Birmingham, AL, June 24-27, 2007;

[5] Carneiro, A., How does knowledge management influence innovation and competitiveness? Journal of Knowledge Management, Vol. 4, no. 2, pp. 8798, 2000;

[6] Cormican, K., O’Sullivan, D., Auditing best practice for effective product innovation management, Technovation, Vol. 24, pp. 819-829, 2004;

[7] Docherty, M. (2006) Primer on open innovation: Principles and practice, PDMAVisions, Nr. 2, pp 13-17;

[8] Galanakis, K.(2006). Innovation process: Make sense using systems thinking,Technovation, 26(11), pp 1222-1232;

[9] Jewkes, J., Sawers, D. and Stillerman, R. The Sources of Invention, 1969 (Macmillan, London);

[10] Johannessen, J. A., Olsen, B., Olaisen, J., Aspects of innovation theory based on knowledgemanagement, International Journal of Information Management, Vol.19, pp.121-139, 1999;

[11] Kim, I.L., O.L. de Weck, W. Nadir, P. Young, and D. Wallace, "Innovative Modern Engineering Design and Rapid Prototyping Course: A Rewarding CAD/CAE/CAM Experience for Undergraduates", American Society of Engineering Education (ASEE) 2004 Annual Conference \& Exposition, Salt Lake City, Utah, June 20-23, 2004;

[12] Lewis, W.P. Further Aspects of Engineering Design Thinking: an Innovative Mechanism, Research Note 01/07, Mechanical Engineering, University of Melbourne, 2007;

[13] Osborn, Alex F., Applied Imagination Principles and Procedures of Creative Thinking, Charles Scribner's Sons, 1957.

[14] Patent US 2011089180 A1

[15] Patent US 5921440 A

[16] Patent US 3076573 A

[17] Patent OSIM-Ro nr 129338 